\title{
Tissue-specific alterations in expression and function of P-glycoprotein in streptozotocin-induced diabetic rats
}

\author{
Lu-lu ZHANG, Liang LU, Shi JIN, Xin-yue JING, Dan YAO, Nan HU, Li LIU, Ru DUAN, Xiao-dong LIU*, Guang-ji WANG, Lin XIE
}

Key Laboratory of Drug Metabolism and Pharmacokinetics, China Pharmaceutical University, Nanjing 210009, China

\begin{abstract}
Aim: To investigate the changes of expression and function of P-glycoprotein (P-GP) in cerebral cortex, hippocampus, liver, intestinal mucosa and kidney of streptozocin-induced diabetic rats.

Methods: Diabetic rats were prepared via a single dose of streptozocin (65 mg/kg, ip). Abcb1/P-GP mRNA and protein expression levels in tissues were evaluated using quantitative real time polymerase chain reaction (QRT-PCR) analysis and Western blot, respectively. P-GP function was investigated via measuring tissue-to-plasma concentration ratios and body fluid excretion percentages of rhodamine 123.

Results: In 5- and 8-week diabetic rats, Abcb1a mRNA levels were significantly decreased in cerebral cortices and intestinal mucosa, but dramatically increased in hippocampus and kidney. In liver, the level was increased in 5-week diabetic rats, and decreased in 8-week diabetic rats. Abcb1b mRNA levels were increased in cerebral cortex, hippocampus and kidney, but reduced in liver and intestinal mucosa in the diabetic rats. Western blot results were in accordance with the alterations of Abcb1a mRNA levels in most tissues examined. P-GP activity was markedly decreased in most tissues of diabetic rats, except kidney tissues.

Conclusion: Alterations in the expression and function of Abcb1/P-GP under diabetic conditions are tissue specific, Abcb1 specific and diabetic duration-dependent.
\end{abstract}

Keywords: diabetes mellitus; ABC superfamily transporter; Abcb1/P-GP gene; P-glycoprotein; rhodamine 123; insulin

Acta Pharmacologica Sinica (2011) 32: 956-966; doi: 10.1038/aps.2011.33; published online 20 Jun 2011

\section{Introduction}

Diabetes mellitus (DM), which is mainly a glucose metabolism disorder, is associated with the development and progression of pathological changes in various organ systems. Several reports have shown that diabetes may also alter the pharmacokinetic behavior of many drugs ${ }^{[1-3]}$, and these changes are generally associated with alterations in functional proteins, including cytochrome P450s (CYP450s) and efflux transporters, which participate in the absorption, metabolism, distribution and excretion of drugs.

The efflux transporters mainly belong to the ABC superfamilies, which comprise P-glycoprotein (P-GP), breast cancer resistance protein (BCRP) and multidrug resistance-associated proteins (MRPs). P-GP is expressed in various tissues, including brain, lung, liver, kidney, gastrointestinal tract, skin and muscle tissue ${ }^{[4,5]}$, and it is considered an important compo-

\footnotetext{
* To whom correspondence should be addressed. E-mail xdliu@cpu.edu.cn

Received 2011-01-20 Accepted 2011-03-23
}

nent of the blood-brain barrier (BBB), blood-placenta barrier, blood-testis barrier and other biological barriers in vivo ${ }^{[6,7]}$. Moreover, P-GP may efflux many substrates, including anticancer agents, calcium channel blockers, antibiotics, cardiac glycosides and immunosuppressants ${ }^{[5,8]}$. Therefore, concomitant administration of drugs usually has been shown to cause drug-drug interactions via the inhibition of P-GP mediated transport ${ }^{[9]}$. For example, Liu et al reported that the level of nimodipine in the rat brain was markedly increased after coadministration of cyclosporin $\mathrm{A}^{[10]}$.

Previous studies have also demonstrated that P-GP expression and function are affected by pathophysiological conditions, such as cancer, diabetes, chronic renal failure and nonalcoholic fatty liver disease $\mathrm{e}^{[11-13]}$. Yu et al found that the intestines of streptozocin (STZ)-induced diabetic rats had higher effective permeabilities of five protoberberine alkaloids, which was accompanied by lowered levels of P-GP protein, indicating an impairment of P-GP function and expression under diabetic conditions ${ }^{[14]}$. Liu et al discovered that diabetes may cause an increase in phenobarbital distribution in the mouse 
brain following an enhancement of the pharmacological activity of phenobarbital in the central nervous system (CNS), suggesting that diabetes may suppress P-GP function and expression in the brains of mice ${ }^{[15]}$; however, the patterns of P-GP alterations appear to be complicated and controversial in certain tissue types. Several reports have demonstrated that diabetes may decrease P-GP function and expression in the brain and intestines ${ }^{[14,16,17]}$, while it also may induce increases in the liver or kidney ${ }^{[18,19]}$. All of the results that have been published indicate that P-GP alterations under diabetic conditions are tissue specific.

We used STZ-induced diabetic rats as a model to verify our hypothesis. The mRNA and protein expression levels of P-GP in the indicated tissues were estimated by QRT-PCR analysis and Western blot, respectively. P-GP function was assessed by measuring the distribution and excretion of rhodamine 123 (Rho123). In addition, the effects of insulin treatment on changes in P-GP expression and function induced by diabetes were also investigated.

\section{Materials and methods Reagents}

Blood glucose reagent kits were purchased from Jiancheng Biotech Co (Nanjing, China). Insulin was purchased from Wanbang Pharmaceutical Co (Xuzhou, China). Primers for the $A b c b 1 a / 1 b$ and $\beta$-actin genes used in QRT-PCR analysis were provided by Realgene Bio-Technologies, Inc (Shanghai, China). The P-glycoprotein monoclonal antibody C219 was obtained from Calbiochem-Novabiochem (Seattle, WA, USA). Streptozocin (STZ), rhodamine 123 (Rho123), pentobarbital and protease inhibitor cocktail were all purchased from Sigma Chemical Co (St Louis, MO, USA). All other reagents were commercially available and were of analytical grade. STZ was dissolved in $0.1 \mathrm{~mol} / \mathrm{L}$ sodium citrate buffer $(\mathrm{pH} 4.5)$. Both Rho123 and pentobarbital were dissolved in physiological saline before use.

\section{Animals}

Male Sprague-Dawley rats, weighing 180-200 g, were purchased from Sino-British Sippr/BK Laboratory Animal Ltd (Shanghai, China). Rats were housed under controlled environmental conditions (temperature, $23 \pm 1{ }^{\circ} \mathrm{C}$; humidity, $55 \% \pm 5 \%$ ) and kept under a 12-h light/dark cycle; commercial food and water were freely available. All animal experiments were performed under a license granted by Jiangsu Science and Technology Office (China) with approval from the Animal Ethics Committee of China Pharmaceutical University. Every effort was made to minimize stress to the animals.

\section{Diabetic model and insulin treatment}

Diabetes was induced in rats by a single injection of STZ (65 mg/kg, ip). The age-matched normal control rats were injected with vehicle. Development of diabetes was confirmed by measuring fasting blood glucose (FBG) levels using a reagent kit. Rats with FBG levels higher than $11.1 \mathrm{mmol} / \mathrm{L}$ on d 7 after STZ injection were considered diabetic ${ }^{[15]}$. The STZ-induced hyperglycemic state is considered a type $1 \mathrm{DM}$ model ${ }^{[20]}$.

The STZ-induced diabetic rats were divided into two groups: diabetic rats and insulin-treated diabetic rats. Insulin $\left(4 \times 10^{4} \mathrm{U} / \mathrm{L}\right)$ was subcutaneously administered to rats at 10 $\mathrm{U} \cdot \mathrm{kg}^{-1} \cdot \mathrm{d}^{-1}$ twice a day for either 5 or 8 weeks. The diabetic rats and age-matched normal control rats received only vehicle. By the end of 5 weeks, half of the whole rats from each group were randomly chosen for measuring $A b c b 1$ mRNA and P-GP protein levels, as well as P-GP activity in the cerebral cortex, hippocampus, liver, intestinal mucosa and kidney following the determination of FBG. The remaining rats continued to be treated for another 3 weeks and then were subjected to the same experiments, as mentioned above.

\section{QRT-PCR analysis}

QRT-PCR analysis was used to measure $A b c b 1$ mRNA levels in the rat cerebral cortex, hippocampus, liver, intestinal mucosa and kidney. The experimental rats were sacrificed under ether anesthesia, and the indicated tissues were quickly obtained. Each tissue, weighing $50 \mathrm{mg}$, was homogenized under ice-cold conditions. The QRT-PCR procedure was conducted as previously described ${ }^{[21-23]}$. Briefly, $2 \mu \mathrm{g}$ of total RNA from each original sample was converted into cDNA for each individual QRT-PCR assay with a 38-cycle three-step PCR using the ABI Prism 7000 thermocycler. The PCR primer sequences are shown in Table 1. Amplifications were performed in a $20 \mu \mathrm{L}$ reaction mixture containing $2.0 \mu \mathrm{L}$ of $10 \times$ PCR buffer, $2.0 \mu \mathrm{L}$ of $25 \mathrm{mmol} / \mathrm{L} \mathrm{MgCl}_{2}, 0.4 \mu \mathrm{L}$ of $10 \mathrm{mmol} / \mathrm{L}$ deoxyribonucleoside triphosphate, $250 \mathrm{nmol} / \mathrm{L}$ of the appropriate forward and reverse primers (Abcb1a/1b and $\beta$-actin), and SYBR green I (Molecular Probes, OR, USA). For normalization of the gene levels, $\beta$-actin was used to correct minor variations in the input RNA amount or inefficiencies of the reverse transcription. The results were calculated according to the manufacturer's instructions ${ }^{[24]}$.

\section{Western blotting}

Western blotting was used for the assessment of P-GP protein expression in the rat cerebral cortex, hippocampus, liver, intestinal mucosa and kidney according to the method previously

Table 1. Primer characteristics of $A b c b 1 a, A b c b 1 b$, and $\beta$-actin.

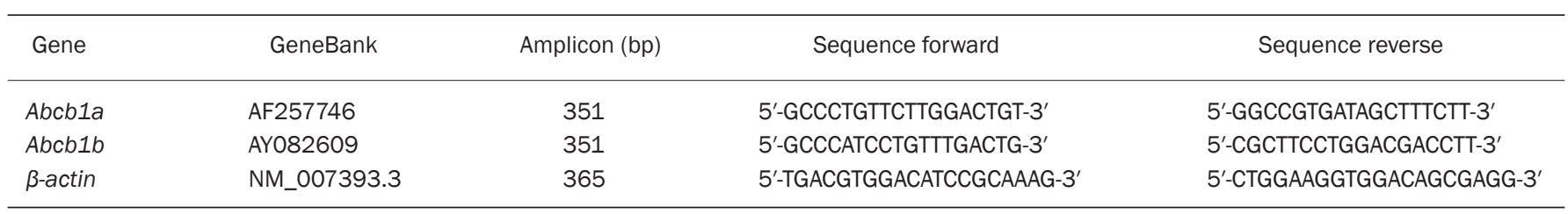


described $^{[25]}$. Rats were sacrificed under ether anesthesia, and the indicated tissues were quickly obtained. Each tissue, weighing $100 \mathrm{mg}$, was homogenized and lysed in lysis buffer containing $10 \mathrm{mmol} / \mathrm{L}$ Tris- $\mathrm{HCl}$ (pH 7.5), $1 \mathrm{mmol} / \mathrm{L}$ EGTA, $1 \mathrm{mmol} / \mathrm{L} \mathrm{MgCl}_{2}, 1 \mathrm{mmol} / \mathrm{L}$ mercaptoethanol, $1 \%$ glycerol and protease inhibitor cocktail $(1 \mathrm{mmol} / \mathrm{L}$ dithiothreitol, 2 $\mathrm{mmol} / \mathrm{L}$ phenylmethylsulfonyl fluoride). Lysates were incubated on ice for $30 \mathrm{~min}$ and centrifuged at $13000 \times \mathrm{g}$ for $10 \mathrm{~min}$ at $4{ }^{\circ} \mathrm{C}$. The supernatants were obtained as membrane fractions for Western blot. Protein concentrations in the solution were measured by the Bio-Rad Protein Assay. An aliquot of each tissue sample was diluted with a volume of $4 \times$ sodium dodecyl sulfate (SDS) sample buffer containing $0.1 \mathrm{~mol} / \mathrm{L}$ Tris$\mathrm{HCl}$ (pH 6.8), 4\% SDS, $200 \mathrm{mmol} / \mathrm{L}$ dithiothreitol, 20\% glycerol, and $0.2 \%$ bromophenol blue. Proteins ( $25 \mu \mathrm{g}$ per lane) were separated by electrophoresis on $8 \%$ SDS-polyacrylamide gels. After electrophoresis, the proteins were electrophoretically transferred to nitrocellulose membranes. Membranes were blocked in phosphate-buffered saline containing $0.1 \%$ Tween-20 (PBST) and 5\% dried skim milk for $60 \mathrm{~min}$ at room temperature and washed three times for $15 \mathrm{~min}$ in PBST. Then the membranes were incubated with the primary monoclonal antibody C219, which was diluted 500-fold in PBST overnight at $4{ }^{\circ} \mathrm{C}$. After removal of the primary antibody, membranes were washed with PBST, incubated with the appropriate HRP-conjugated goat anti-mouse secondary antibody at room temperature for another $1 \mathrm{~h}$ and washed again three times in PBST. The transferred proteins were incubated with enhanced chemiluminescence substrate solution for $5 \mathrm{~min}$, according to the manufacturer's instructions, and visualized with autoradiography X-ray film. The relative levels were quantified densitometrically with Quantity One Software (Bio-Rad Laboratories, Richmond, CA, USA) and calculated according to the reference bands of the protein glyceraldehyde phosphate dehydrogenase (GAPDH).

\section{Tissue distribution of Rho123}

To elucidate the changes in P-GP function in the rat cerebral cortex, hippocampus, liver, intestinal mucosa and kidney, Rho123 (0.2 mg/kg) was intravenously administered to the rats. At $45 \mathrm{~min}$ after administration, the rats were sacrificed under light ether anesthesia, and then the indicated tissues and blood samples were harvested to measure the concentrations of Rho123 ${ }^{[16]}$.

\section{Biliary excretion, intestinal fluid excretion and urinary excretion of Rho123}

To confirm the changes in P-GP function in the rat liver, intestinal mucosa and kidney, we analyzed biliary excretion, intestinal fluid excretion and urinary excretion. On the day of the experiment, several rats from each group were randomly chosen and immediately housed in individual metabolic cages following the injection of Rho123 $(0.2 \mathrm{mg} / \mathrm{kg}$, iv). Urine was collected from 0 to $6 \mathrm{~h}, 0$ to $12 \mathrm{~h}$, and 0 to $24 \mathrm{~h}$.

To evaluate the biliary excretion and intestinal exsorption of Rho123, in situ single pass perfusion was performed, as previously described ${ }^{[14]}$. Rats were anesthetized by an intraperitoneal injection of pentobarbital sodium $(45 \mathrm{mg} / \mathrm{kg})$. The small intestine was exposed by midline abdominal incision. The end of the proximal ileum (about $4 \mathrm{~cm}$ above the junction with the cecum) was cannulated with import-resistant silicone tubing (id $1 \mathrm{~mm}$ ). The end of distal ileum (just above the junction with the caecus) was cannulated with silicone tubing (id $4 \mathrm{~mm}$ ) as well. The bile duct was also cannulated with polyethylene tubing (PE10). Intestinal segments were perfused at a constant rate $(0.2 \mathrm{~mL} / \mathrm{min})$ by a pump with physiological saline. Then the intestines were returned to the abdominal cavity. The abdomen was covered with saline-saturated gauze to maintain the moisture levels. The rats immediately received Rho123 (0.2 mg/ kg) via the tail vein following the surgery. Then bile samples and intestinal fluid samples were collected every $30 \mathrm{~min}$ up to $180 \mathrm{~min}$. At the same time, blood was collected via the jugular vein, and plasma from the samples was obtained by centrifugation. The plasma, bile, intestinal fluid and urine samples were stored at $-20{ }^{\circ} \mathrm{C}$ until further analysis. The accumulated excretion percentages were calculated, and the area under curve of plasma concentration ( $\mathrm{AUC}_{0-180 \mathrm{~min}}$ ) was estimated using the linear trapezoidal rule.

\section{Sample assays}

The concentrations of Rho123 in the tissues, bile, intestinal fluid, urine and plasma were measured by HPLC according to the method previously described ${ }^{[15,25]}$. The HPLC system consisted of a Shimadzu LC-10Avp system (Shimadzu, Japan), Diamonsil C18, $150 \mathrm{~mm} \times 4.6 \mathrm{~mm}$ id, a $5 \mu \mathrm{m}$ particle size column (Richmond Hill, ON, USA) and a fluorescence detector $\left(\mathrm{RF}-10 \mathrm{~A}_{\mathrm{XL}}\right)$ set at an excitation wavelength of $485 \mathrm{~nm}$ and an emission wavelength of $546 \mathrm{~nm}$. One hundred microliters of plasma, bile, intestinal fluid, urine and tissue homogenate were vortexed with $300 \mu \mathrm{L}$ methanol for $10 \mathrm{~min}$. After centrifugation, $200 \mu \mathrm{L}$ of the supernatant was taken out and centrifuged again. Twenty microliters of the supernatant was injected into the HPLC system. The mobile phase consisted of $0.1 \%$ glacial acetic acid $(\mathrm{pH} 4.0)$ and acetonitrile $(7: 3, v / v)$, and the flow rate was set at $1.0 \mathrm{~mL} / \mathrm{min}$. The lowest limits of quantitation of Rho123 were $1.0 \mathrm{ng} / \mathrm{g}$ in the brain; $12.5 \mathrm{ng} / \mathrm{g}$ in the liver; $50000 \mathrm{ng} / \mathrm{g}$ in the intestinal mucosa; $125.0 \mathrm{ng} / \mathrm{g}$ in the kidney; $7.8 \times 10^{-2} \mathrm{~g} / \mathrm{L}$ in the bile; $3.1 \times 10^{-3} \mathrm{~g} / \mathrm{L}$ in the intestinal fluid; $3.1 \times 10^{-2} \mathrm{~g} / \mathrm{L}$ in the urine; and $1.6 \times 10^{-2} \mathrm{~g} / \mathrm{L}$ in the plasma. The recoveries were higher than $85 \%$, and the relative standard deviations of the intra-day and inter-day in samples were lower than $10 \%$.

\section{Statistical analyses}

Results were expressed as the mean \pm standard deviation (SD). The overall differences among groups were determined by one-way of analysis of variance (ANOVA). If the differences were significant, they were estimated using the Student-Newman-Keuls multiple comparison post hoc test. A P-value of less than 0.05 indicates a significant difference. 


\section{Results}

Physiological and biochemical parameters of experimental rats

The physiological and biochemical parameters of the rats 5 or 8 weeks after streptozotocin or vehicle treatment were measured and listed in Table 2. Compared with the age-matched normal control rats, lower body weights and higher levels of blood glucose were found in STZ-induced diabetic rats $(P<0.01)$. Insulin treatment reversed the changes induced by diabetes $(P<0.01)$.

\section{Levels of Abcb1 mRNA}

In rodents, $A b c b 1 / \mathrm{P}-\mathrm{GP}$ exists as two functional isoforms that are encoded by two different genes: $A b c b 1 a$ and $A b c b 1 b$. QRTPCR was used to measure levels of $A b c b 1 a / 1 b$ mRNA in the indicated tissues. mRNA levels of these genes were normalized to the cycle threshold values for the housekeeping gene $\beta$-actin. The results show that $A b c b 1 a$ mRNA levels are tissue specific (Figure 1). Among the indicated tissues of agematched normal control rats, the highest levels were found in the cerebral cortex and the lowest levels were located in the kidney. The levels of Abcb1a mRNA in the brain also varied among different regions; for example, Abcb1a mRNA levels in the cerebral cortex were significantly higher than those in the hippocampus. The induction of diabetes resulted in tissue-
Table 2. Effects of diabetes and insulin treatment on body weight and blood glucose of experimental rats.

\begin{tabular}{llccc}
\hline $\begin{array}{l}\text { Treatment } \\
\text { time }\end{array}$ & Parameters & Control & Diabetes & $\begin{array}{c}\text { Diabetes+ } \\
\text { insulin }\end{array}$ \\
\hline 5-week & body weight (g) & $392 \pm 21$ & $193 \pm 7^{\mathrm{c}}$ & $308 \pm 18^{f}$ \\
& blood glucose (mmol/L) & $6.7 \pm 0.9$ & $31.7 \pm 2.9^{\circ}$ & $6.7 \pm 3.1^{f}$ \\
8-week & body weight (g) & $438 \pm 14$ & $223 \pm 28^{\circ}$ & $370 \pm 22^{f}$ \\
& blood glucose (mmol/L) & $6.5 \pm 1.1$ & $31.0 \pm 2.9^{\circ}$ & $4.7 \pm 3.0^{f}$ \\
\hline
\end{tabular}

The insulin-treated rats (Diabetes+insulin) were subcutaneouly administered insulin at $10 \mathrm{U} \cdot \mathrm{kg}^{-1} \cdot \mathrm{d}^{-1}$ twice a day for consecutive 5 or 8 weeks. The STZ-induced diabetic rats (Diabetes) and age-matched normal control rats (Control) only received vehicle. Data are shown as mean $\pm S D$ of twenty rats. ${ }^{\mathrm{C}} P<0.01$ vs control group; ${ }^{\mathrm{f}} P<0.01$ vs diabetic group.

specific and duration-dependent changes in the $A b c b 1 a$ mRNA levels. Abcb1a mRNA levels were clearly down-regulated in the cerebral cortices and intestinal mucosa of diabetic rats, while up-regulations were observed in the hippocampi and kidneys of these rats. In the liver, increased $A b c b 1 a$ mRNA levels were found in 5-week diabetic rats, but clear decreases were noted in 8-week diabetic rats. We postulated that insu-
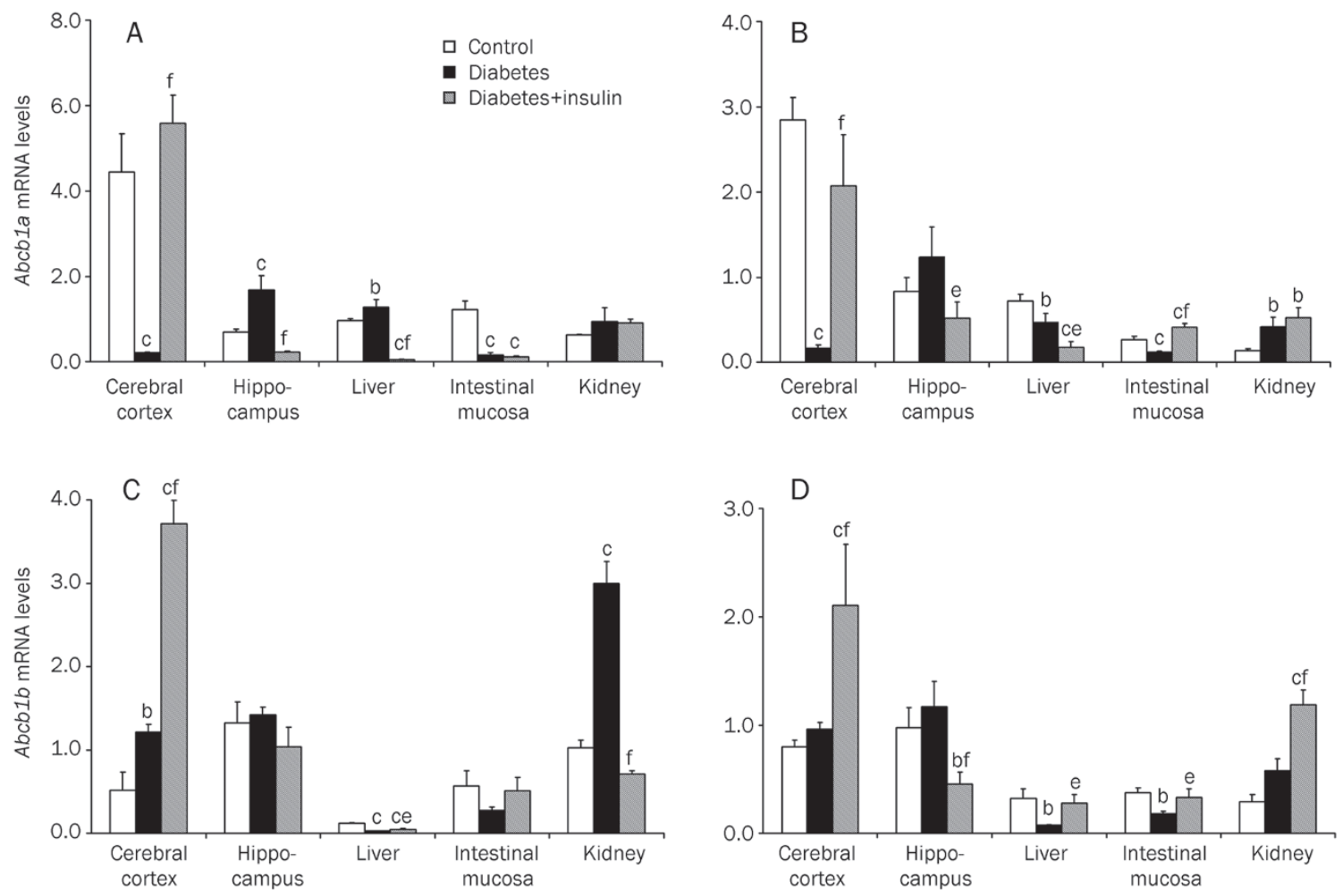

Figure 1. Effects of diabetes on $A b c b 1 a / 1 b$ mRNA levels in the rat cerebral cortex, hippocampus, liver, intestinal mucosa and kidney. Insulin-treated rats ( $₫$, Diabetes+insulin) were subcutaneously administered insulin at a concentration of $10 \mathrm{U} \cdot \mathrm{kg}^{-1} \cdot \mathrm{d}^{-1}$ twice a day consecutively for 5 or 8 weeks. STZinduced diabetic rats ( $\square$, Diabetes) and age-matched normal control rats ( $\square$, Control) only received vehicle. Relative staining intensity for Abcb1a mRNA levels in the indicated tissues of 5-week (A) and 8-week (B) experimental rats and Abcb1b mRNA levels in the indicated tissues of 5-week (C) and 8-week (D) experimental rats are presented. Each data point represents the mean \pm SD of four rats. ${ }^{\mathrm{b}} P<0.05$, ${ }^{\mathrm{C}} P<0.01$ vs control group; ${ }^{\mathrm{e}} P<0.05$, ${ }^{\mathrm{f}} P<0.01$ vs diabetic group. 
lin treatment might improve the altered $A b c b 1 a$ mRNA levels induced by diabetes in tissue-specific and duration-dependent manners. It was evident that insulin treatment blocks the down-regulation of Abcb1a mRNA levels in the cerebral cortices of diabetic rats. Conversely, insulin treatment further suppressed $A b c b 1 a$ mRNA levels in the hippocampus and liver of diabetic rats, which led to lower levels of Abcb1a mRNA in the hippocampus and liver of insulin-treated rats compared to age-matched normal control rats. We also observed that insulin treatment only improved Abcb1a mRNA levels in the intestinal mucosa of 8-week diabetic rats. The levels of $A b c b 1 a$ mRNA in the kidneys of diabetic rats were not improved by insulin treatment.

$A b c b 1 b$ mRNA levels were also different among various tissues. In the age-matched normal control rats, the levels in the hippocampus were the highest and the levels in the liver were the lowest. We also noted that the levels of $A b c b 1 b$ mRNA in various tissues were quite different from those of $A b c b 1 a$ mRNA in the same tissues. For example, in the cerebral cortex, the $A b c b 1 b$ mRNA levels were significantly lower than the levels of Abcb1a mRNA. Diabetes also altered $A b c b 1 b$ mRNA levels in a tissue-specific manner. Clear decreases were found in the intestinal mucosa and livers of diabetic rats, while upregulations were present in the cerebral cortices and kidneys. However, diabetes did not affect $A b c b 1 b$ mRNA levels in the hippocampus. Insulin treatment resulted in differential effects on $A b c b 1 b$ mRNA levels in various tissues. Insulin treatment further increased $A b c b 1 b$ mRNA levels in the cerebral cortex but suppressed its levels in the hippocampus of diabetic rats, causing lower levels of $A b c b 1 b$ mRNA in the hippocampus compared with age-matched normal control rats. We also found that insulin treatment partly blocked the down-regulation of $A b c b 1 b$ mRNA levels in the intestinal mucosa and liver of diabetic rats. The effects of insulin treatment on $A b c b 1 b$ mRNA levels in the kidneys of diabetic rats were dependent on the duration of diabetes. Insulin treatment reversed the up-regulation of $A b c b 1 b$ mRNA levels in 5-week diabetic rats, but further enhanced $A b c b 1 b$ mRNA levels of 8-week diabetic rats.

\section{Expression of P-GP protein}

Western blotting was used to investigate P-GP protein expression in the indicated tissues. The results revealed a band of $170 \mathrm{kDa}$ that corresponded to P-GP. We found that the effects of diabetes on P-GP expression were also tissue specific (Figure 2). Up-regulations were observed in the hippocampus and kidney of diabetic rats, but clear decreases in P-GP expression were shown in the cerebral cortex, liver and intestinal mucosa. These findings were in good accordance with the changes in $A b c b 1 a$ mRNA levels in most tissues. Although $A b c b 1 b$ mRNA levels were increased in the cerebral cortex of diabetic rats, lowered total expression of P-GP protein was still found, indicating that $A b c b 1 b$ mRNA has minor contributions to P-GP expression in the cerebral cortex. Similarly, up-regulation of Abcb1a mRNA levels was found in the liver of diabetic rats, but P-GP expression was decreased, suggesting that $A b c b 1 a$
mRNA has a nominal contribution to P-GP expression in the liver. Insulin treatment partly reversed the alterations induced by diabetes in most tissues. Nevertheless, insulin treatment further enhanced P-GP expression in the kidneys of 8-week diabetic rats.

\section{Tissue distribution of Rho123}

To investigate whether the alterations of P-GP expression induced by diabetes affected P-GP functional activity, Rho123 distribution in the indicated tissues was estimated. The tissueto-plasma concentration ratio (ie, $K_{\mathrm{p}}$ ) was calculated as an index of P-GP functional activity. The results (Table 3) indicate that diabetes increased the concentrations of Rho123 in most tissues, leading to higher tissue-to-plasma concentration ratios. However, a lower tissue-to-plasma concentration ratio was found in the kidneys of 8-week diabetic rats. We also noted that the extent of changes in the tissue-to-plasma concentration ratios of 5-week diabetic rats was higher than that of 8-week diabetic rats. Insulin treatment also partly reversed the changes in P-GP functional activity induced by diabetes.

\section{Biliary excretion, intestinal fluid excretion and urinary excretion of Rho123}

The functional activities of P-GP in the liver, intestinal mucosa and kidney were further evaluated by measuring the biliary excretion, intestinal fluid excretion and urinary excretion of Rho123, respectively. The plasma $\mathrm{AUC}_{0-180 \text { min }}$ was also estimated. The results show that plasma $\mathrm{AUC}_{0-180 \text { min }}$ was not affected in 5-week diabetic rats, but lower exposure of Rho123 was found in the plasma of 8-week diabetic rats (Figure 3). A clear decrease in biliary excretion of Rho123 was observed in diabetic rats; however, intestinal fluid excretion of Rho123 in diabetic rats had only an indistinctive downward trend. In contrast, diabetes increased urinary excretion of Rho123. The results indicate that diabetes may decrease P-GP function in the liver and intestinal mucosa, but it increases P-GP function in the kidney, which is in agreement with the P-GP expression findings. Five-week insulin treatment further enhanced the decreases in biliary excretion and intestinal fluid excretion of Rho123, but 8-week insulin treatment reversed the declines induced by diabetes. However, insulin treatment did not improve the effect on Rho123 urinary excretion in 8-week diabetic rats.

\section{Discussion}

The present study was undertaken to investigate the effects of diabetes on P-GP expression and function in the cerebral cortex, hippocampus, liver, intestinal mucosa and kidney. The results clearly demonstrate that alterations in P-GP expression and function under diabetic conditions were tissue specific and diabetic duration dependent.

Our QRT-PCR analysis (Figure 1) showed that $A b c b 1$ mRNA levels are tissue specific. The highest level of Abcb1a mRNA was found in the cerebral cortex of age-matched normal control rats, while the kidneys had the lowest levels of $A b c b 1 a$ mRNA. We also found that the levels of $A b c b 1 b$ mRNA were 
A
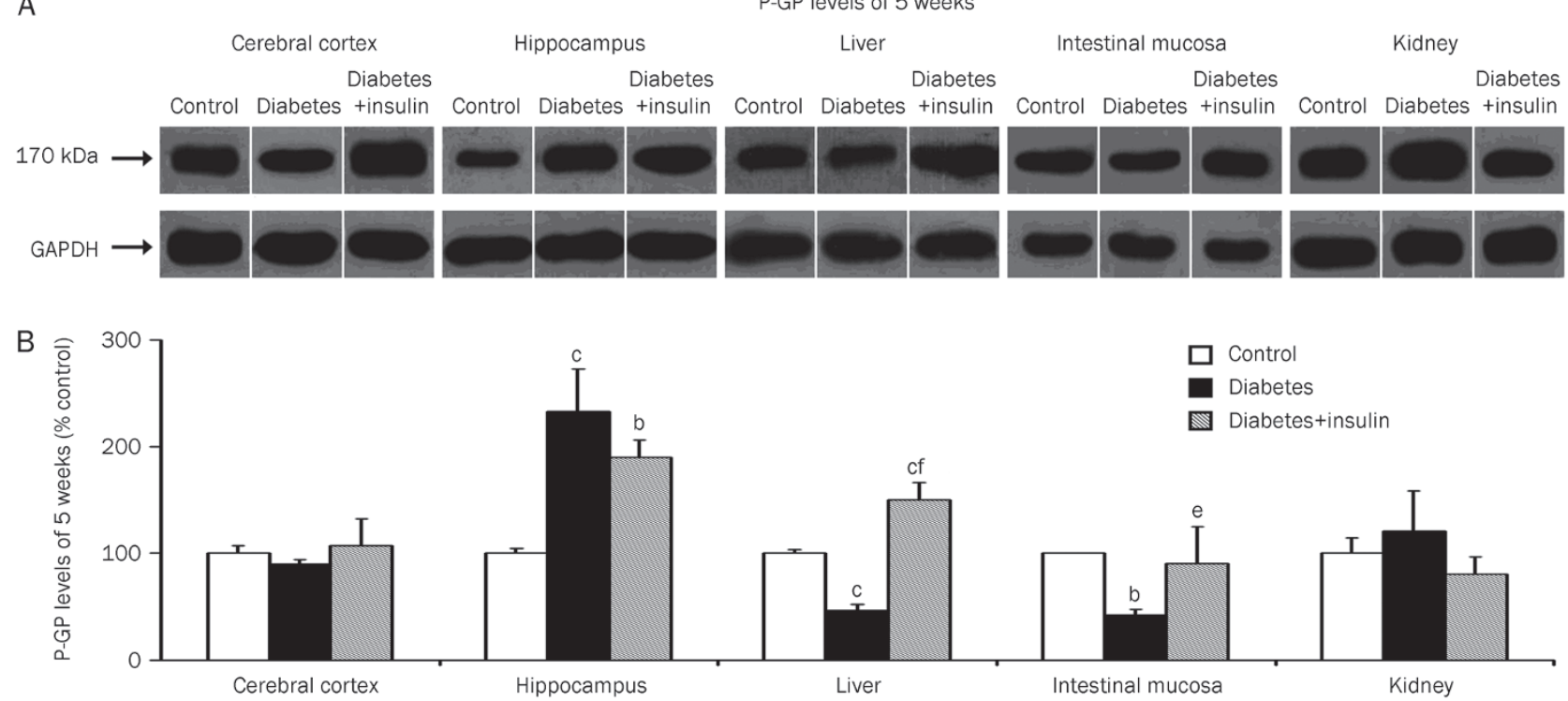

C
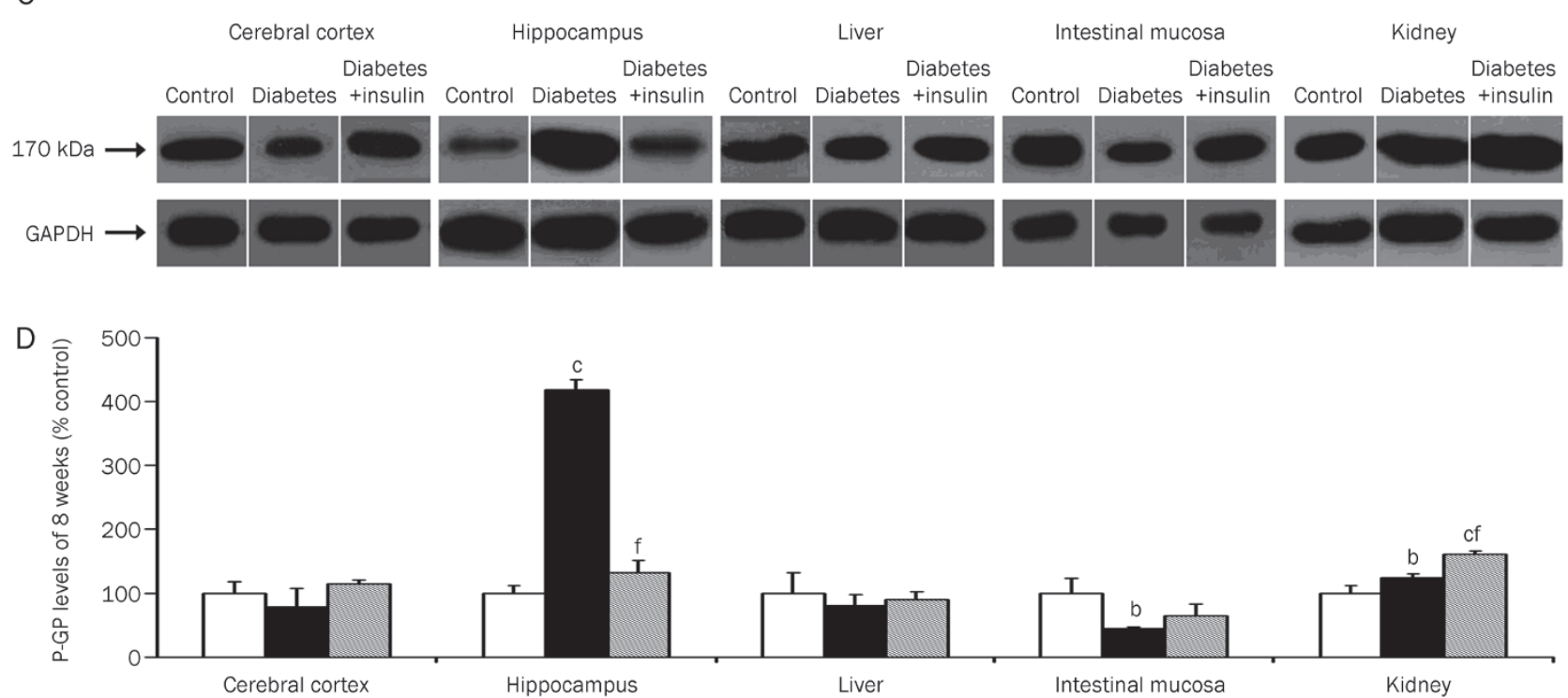

Figure 2. Effects of diabetes on P-GP protein levels in the rat cerebral cortex, hippocampus, liver, intestinal mucosa and kidney. Insulin-treated rats ( $₫$, Diabetes+insulin) were subcutaneously administered insulin at a concentration of $10 \mathrm{U} \cdot \mathrm{kg}^{-1} \cdot \mathrm{d}^{-1}$ twice a day consecutively for 5 or 8 weeks. STZ-induced diabetic rats ( $\square$, Diabetes) and age-matched normal control rats ( $\square$, Control) only received vehicle. Representative Western blots of P-GP in the indicated tissues of 5-week (A) and 8-week (C) experimental rats and the ratio of relative intensities of P-GP in the indicated tissues of 5-week (B) and 8-week (D) experimental rats are described. Each band corresponding to $170 \mathrm{kDa}$ was analyzed. Data are shown as the mean \pm SD of four rats. ${ }^{\mathrm{b}} P<0.05,{ }^{\mathrm{C}} P<0.01$ vs control group; ${ }^{e} P<0.05,{ }^{f} P<0.01$ vs diabetic group.

quite different from those of Abcb1a mRNA in the corresponding tissues. The effects of diabetes on $A b c b 1$ mRNA levels were also tissue specific, $A b c b 1$ specific and diabetic duration dependent. Clear down-regulations of $A b c b 1 a$ mRNA levels were observed in the cerebral cortex and intestinal mucosa of diabetic rats. On the contrary, up-regulations of $A b c b 1 a$ mRNA levels were noted in the kidney and hippocampus. However, the changes in the Abcb1a mRNA levels in the livers of diabetic rats were dependent on the duration of diabetes.
Abcb1a mRNA levels were increased in 5-week diabetic rats but decreased in 8-week diabetic rats in the liver. However, we found that the alterations in $A b c b 1 b$ mRNA levels were different from Abcb1a mRNA levels. Although decreases in $A b c b 1 b$ mRNA levels were observed in the liver and intestinal mucosa, increased levels of $A b c b 1 b$ mRNA were shown in the cerebral cortex and kidney of diabetic rats. In the hippocampus, the $A b c b 1 b$ mRNA levels were not significantly affected by diabetes. Surprisingly, $A b c b 1 b$ mRNA levels increased 
Table 3. Effects of diabetes on Rho123 distribution in cerebral cortex, hippocampus, liver, intestinal mucosa and kidney of experimental rats.

\begin{tabular}{|c|c|c|c|}
\hline & Control & Diabetes & Diabetes+insulin \\
\hline \multicolumn{4}{|l|}{ 5-week } \\
\hline Cerebral cortex (ng/g) & $4.28 \pm 0.14$ & $5.15 \pm 0.43^{b}$ & $3.80 \pm 0.26^{f}$ \\
\hline$K_{p}($ cerebral cortex, mL/g) & $0.09 \pm 0.01$ & $0.17 \pm 0.01^{c}$ & $0.09 \pm 0.01^{\dagger}$ \\
\hline Hippocampus (ng/g) & $4.62 \pm 0.63$ & $6.26 \pm 1.32$ & $7.11 \pm 2.59$ \\
\hline$K_{p}($ liver, mL/g) & $1.16 \pm 0.26$ & $6.17 \pm 1.41^{\mathrm{C}}$ & $1.87 \pm 0.87^{f}$ \\
\hline Intestinal mucosa (ng/g) & $451811 \pm 68825$ & $527034 \pm 14232$ & $275987 \pm 76654^{b}$ \\
\hline$K_{\mathrm{p}}$ (intestinal mucosa, $\mathrm{mL} / \mathrm{g}$ ) & $12653 \pm 3375$ & $17345 \pm 1224$ & $6308 \pm 1819^{b f}$ \\
\hline Kidney (ng/g) & $784.2 \pm 237.7$ & $976.9 \pm 114.9$ & $594.4 \pm 195.3^{e}$ \\
\hline$K_{\mathrm{p}}$ (kidney, mL/g) & $17.7 \pm 4.7$ & $32.7 \pm 5.3^{c}$ & $13.3 \pm 5.1^{f}$ \\
\hline$K_{\mathrm{p}}($ cerebral cortex, mL/g) & $0.10 \pm 0.01$ & $0.13 \pm 0.02$ & $0.09 \pm 0.01^{f}$ \\
\hline Hippocampus (ng/g) & $3.70 \pm 0.20$ & $3.69 \pm 0.47$ & $4.37 \pm 0.64$ \\
\hline$K_{\mathrm{p}}$ (hippocampus, mL/g) & $0.10 \pm 0.02$ & $0.15 \pm 0.02^{c}$ & $0.11 \pm 0.02^{f}$ \\
\hline Liver (ng/g) & $69.4 \pm 10.2$ & $66.6 \pm 6.2$ & $120.9 \pm 34.1^{\text {be }}$ \\
\hline$K_{\mathrm{p}}$ (liver, $\mathrm{ml} / \mathrm{g}$ ) & $1.77 \pm 0.11$ & $2.70 \pm 0.27$ & $2.98 \pm 0.85^{b}$ \\
\hline Intestinal mucosa (ng/g) & $101135 \pm 23658$ & $77296 \pm 8577$ & $210123 \pm 55354^{\mathrm{bf}}$ \\
\hline$K_{p}$ (intestinal mucosa, mL/g) & $2777 \pm 366$ & $3087 \pm 331$ & $5170 \pm 1321$ \\
\hline Kidney (ng/g) & $422.5 \pm 103.2$ & $149.3 \pm 34.1^{\mathrm{C}}$ & $578.0 \pm 139.9^{b f}$ \\
\hline$K_{\mathrm{p}}($ kidney, $\mathrm{mL} / \mathrm{g})$ & $17.9 \pm 3.4$ & $5.9 \pm 1.4^{c}$ & $14.2 \pm 3.2^{f}$ \\
\hline
\end{tabular}

The insulin-treated rats (Diabetes+insulin) were subcutaneouly administered insulin at $10 \mathrm{U} \cdot \mathrm{kg}^{-1} \cdot \mathrm{d}^{-1}$ twice a day for consecutive 5 and 8 weeks. The STZinduced diabetic rats (Diabetes) and age-matched normal control rats (Control) only received vehicle. The concentrations of Rho123 in plasma and tissues were measured at $45 \mathrm{~min}$ followed administration of Rho123 (0.2 mg/kg, iv). Each data represents the mean $\pm S D$ of five rats. Intestinal mucosa was represented by $\mathrm{ng} / \mathrm{g}$ protein, while brain, liver and kidney were represented by $\mathrm{ng} / \mathrm{g}$ tissue. $K_{\mathrm{p}}$ represents the tissue-to-plasma concentration ratio. ${ }^{\mathrm{b}} P<0.05,{ }^{\mathrm{c}} P<0.01$ vs control group; ${ }^{\mathrm{e}} P<0.05,{ }^{\mathrm{f}} P<0.01$ vs diabetic group.
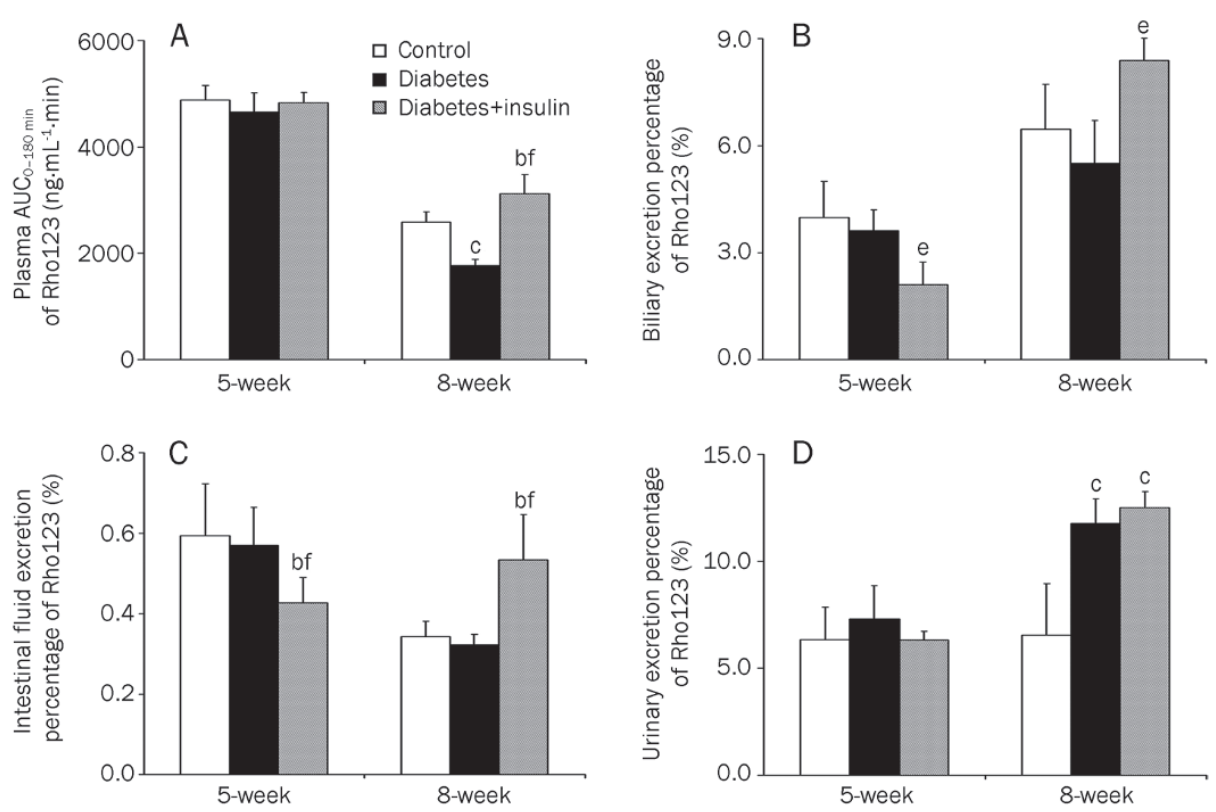

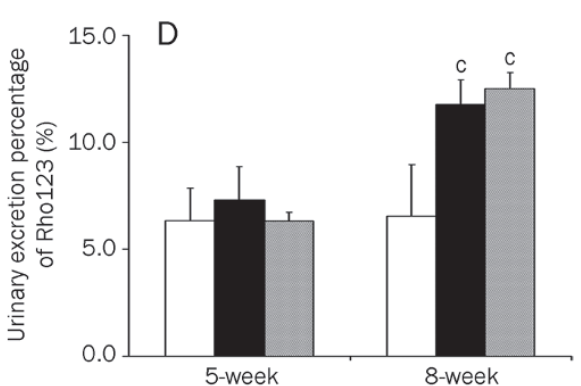

Figure 3. Effects of diabetes on plasma $\mathrm{AUC}_{0-180 \mathrm{~min}}(\mathrm{~A})$ and accumulated excretion percentages of Rho123 in biliary fluid (B), intestinal fluid (C) and urine (D). Insulintreated rats ( $\square$, Diabetes+insulin) were subcutaneously administered insulin at a concentration of $10 \mathrm{U} \cdot \mathrm{kg}^{-1} \cdot \mathrm{d}^{-1}$ twice a day consecutively for 5 or 8 weeks. STZ-induced diabetic rats ( $\mathbf{\square}$, Diabetes) and age-matched normal control rats ( $\square$, Control) only received vehicle. Each data point represents the mean \pm SD of five rats. ${ }^{b} P<0.05,{ }^{c} P<0.01$ vs control group; ${ }^{\mathrm{e}} P<0.05,{ }^{\mathrm{f}} P<0.01$ vs diabetic group. 
rather than decreased in the cerebral cortex of diabetic rats. The reason and mechanism for the different alterations in the two $A b c b 1$ isoforms remain unknown, although it has been proposed that alterations in $A b c b 1 b$ mRNA levels may compensate for the changes of $A b c b 1 a^{[26]}$. In addition to their common function as a drug efflux transporter, the $A b c b 1$ isoforms appear to have their own specific function: $A b c b 1 a$ was reported to regulate cell volume by influencing swelling activated chloride currents via a protein kinase $C$ sensitive phosphorylation site on P-GP ${ }^{[27]}$, while $A b c b 1 b$ has been shown to be involved in apoptosis ${ }^{[2]}$ and cellular stress ${ }^{[29,30]}$. However, these views remain controversial ${ }^{[31,32]}$.

The expression levels of P-GP protein in the indicated tissues were measured by Western blot. The results show that P-GP levels were decreased in the cerebral cortex, liver and intestinal mucosa of diabetic rats, while they were increased in the hippocampus and kidney (Figure 2). These results are in good accordance with the alterations in $A b c b 1$ mRNA levels in most tissues. Although $A b c b 1 b$ mRNA levels in the cerebral cortex of diabetic rats were increased, we found lowered P-GP expression. This result indicates that $A b c b 1 b$ has a nominal contribution to P-GP expression in the cerebral cortex. We also observed that $A b c b 1 a$ mRNA levels in the liver of 5-week diabetic rats were increased, but P-GP expression was still decreased, suggesting that the expression of P-GP in the liver is mainly attributed to translation of $A b c b 1 b$. This hypothesis is supported by a previous report ${ }^{[33]}$.

Rho123, a typical substrate of P-GP, has been widely used as an index of P-GP mediated transport in in vitro and in vivo studies $^{[34-40]}$. In the present study, Rho123 also served as a marker for evaluating P-GP function. The tissue-to-plasma concentration ratio and the biliary excretion, intestinal fluid excretion and urinary excretion of Rho123 were used for assaying P-GP activity in indicated tissues including cerebral cortex, hippocampus, liver, intestinal mucosa and kidney. The results demonstrate that clear increases in the tissue-to-plasma concentration ratios were found in most tissues of diabetic rats, while there was a decrease in the ratio in the kidney of 8 -week diabetic rats. As the results show (Table 3), the higher tissue-to-plasma concentration ratios were due to lowered plasma concentrations and increased tissue concentrations. The decrease in Rho123 exposure in the plasma may result from increases of P450s or other metabolism-related enzymes induced by diabetes ${ }^{[41]}$, and the increase in urinary excretion of Rho123 that we observed may also contribute to a decrease of exposure. The increased levels of Rho123 in various tissues may result from an impairment in tissue barrier integrity or P-GP function. In the brain, P-GP is mainly expressed on the luminal membrane of brain microvessel endothelia and extrudes its substrate from brain to plasma. The increases in tissue-to-plasma concentration ratios in the brain indicate that there is an impairment of P-GP function in the BBB. This finding in the cerebral cortex is in accordance with the alterations of P-GP expression and agrees with our previous reports ${ }^{[15,16]}$. Amazingly, although P-GP protein expression was increased in the hippocampi of diabetic rats, the tissue-to-plasma con- centration ratio was still increased. This indicates that there are some factors that cause a decrease in the binding affinity of P-GP to its substrate or to ATP, which contributes to lowered efflux activity of P-GP. The alteration in cell-cell contact ${ }^{[42]}$ and disruption of tight junctions ${ }^{[43,44]}$ in the BBB of diabetic rats may be the causes of the increases in the tissue-to-plasma concentration ratios in the brain.

P-GP is also expressed on the apical membranes of the canalicular membranes of hepatocytes, intestinal mucosa and proximal tubules. P-GP acts as an excretion pump and excretes its substrates from cells to the bile, intestinal fluid and urine. Therefore, alterations in the tissue-to-plasma concentration ratios may reflect changes in Rho123 uptake via cells and alterations in tissue excretory functions. Lowered biliary excretion of Rho123 in diabetic rats (Figure 3) may partly explain the increases in the liver-to-plasma concentration ratio, indicating the impairment of P-GP function in the liver. The intestinal fluid excretion of Rho123 in diabetic rats only showed a small downward trend. The decreases in biliary excretion and intestinal fluid excretion were also in accordance with the P-GP expression levels in the liver and intestinal mucosa. Although the increased excretion of Rho123 in the urine and the enhanced expression of P-GP in the kidney may partly explain the decreased kidney-to-plasma concentration ratio of 8-week diabetic rats, the finding did not explain the fact that the kidney-to-plasma concentration ratio was increased in 5-week diabetic rats. The mechanism that gives rise to this phenomenon remains unclear, but it does not exclude the possibility of increased uptake via the kidney.

Reduced insulin levels in plasma are one of the significant features of diabetes. Therefore, we investigated the effects of insulin treatment on the expression and function of $A b c b 1 /$ P-GP under diabetic conditions. We found that expression of $A b c b 1 / P-G P$ in various tissues showed different sensitivity to insulin. The levels of Abcb1a mRNA in the cerebral cortex and intestinal mucosa were highly dependent on insulin levels; thus, insulin treatment nearly restored the levels of $A b c b 1 a$ mRNA in the cerebral cortex and intestinal mucosa of diabetic rats to the values of age-matched normal control rats. In contrast, insulin inhibited the expression of $A b c b 1$ in the hippocampus. In addition to insulin deficiency, diabetes has been linked to increased levels of systemic inflammatory mediators, such as cytokines, which have been reported to regulate the function and expression of P-GP $P^{[45-47]}$. All of these results indicate that expression of $A b c b 1 /$ P-GP in various tissues might be regulated by different factors, and this deduction has been supported by many reports. Nawa et al reported that decreases in P-GP expression in the intestines of diabetic mice are correlated with iNOS activity. Co-administration of the iNOS inhibitors L- $N^{G}$-nitroarginine ester and aminoguanidine has been shown to attenuate the decrease in P-GP expression induced by diabetes ${ }^{[17]}$. However, Liu et al found that the decrease in expression and function of BCRP in the cerebral cortex could not be reversed by co-administration of aminoguanidine ${ }^{[48]}$. Zhao et al proposed that endotoxin decreases P-GP levels in the brains of mice ${ }^{[49]}$, but Heemskerk 
et al showed that endotoxin increases the expression of Abcb1/ P-GP in the rat kidney ${ }^{[50]}$. A further study showed that the up-regulation of $A b c b 1 /$ P-GP may be mediated by iNOS activity and that co-administration of aminoguanidine may block expression of $A b c b 1 / P-G P$ induced by endotoxin. With regard to $A b c b 1 / P-G P$ expression in diabetic animals, the reports remain conflicting. Tramonti et al reported that both renal tubular $A b c b 1 a$ and $A b c b 1 b$ mRNA levels were significantly upregulated in sham-operated diabetic rats (SD) compared with sham-operated control rats (SN) on the 14th day after administration of STZ, but more marked alterations in Abcb1a mRNA levels were found compared with $A b c b 1 b$ levels ${ }^{[18]}$. On the contrary, Anger et al found that liver $A b c b 1 a$ mRNA levels were significantly down regulated, but the levels of $A b c b 1 b$ mRNA were unaffected in the rats on the 9th day after STZ administration. Renal Abcb1a showed a downward trend ${ }^{[51]}$. Liu et al proposed that $A b c b 1 a$ levels were suppressed in the cerebral cortex of 3-week and 5-week diabetic rats, while $A b c b 1 b$ levels were decreased in 3-week diabetic rats but increased in 5-week diabetic rats ${ }^{[31]}$. However, Reichel et al reported that P-GP and BCRP expression levels were increased in blood-brain barrier capillaries on the 14th day after STZ administration. In the choroid plexus, only BCRP showed elevated gene expression. Protein expression was not altered, and the functional capability of P-GP and BCRP also showed no change ${ }^{[52]}$. The discrepancy among these studies may be due to differences in the tissues and duration of diabetes, as well as the isoform of $A b c b 1$. Our present study demonstrates that the effects caused by the onset of diabetes on $A b c b 1 /$ P-GP expression are tissue specific, and they are also dependent on the $A b c b 1$ isoform and the duration of diabetes. Furthermore, the findings in the present study may partly explain the above discrepancy.

Considering that P-GP regulates the absorption, distribution and excretion of various medicines, the alterations in P-GP expression under diabetic conditions may lead to significant alterations in the distribution of drugs, bringing about changes in toxicological/pharmacological activity. For example, the pharmacological activities of phenobarbital in the $\mathrm{CNS}^{[15]}$ and of second-generation histamine HI-receptor antagonists ${ }^{[20]}$ were reported to be enhanced in diabetic mice.

Previous studies have shown that besides medical agents, P-GP also transports some physiological substrates, such as steroid hormones and $\beta$-amyloid ${ }^{[3,54]}$, and that P-GP may regulate ion channel activity via direct interaction, suggesting that functional alteration of P-GP has a significant impact on the physiological environment ${ }^{[55]}$. For instance, alterations in steroid hormones levels were reported to be involved in the development of depression, indicating that the changes in P-GP function under diabetic conditions may be related to depressive symptoms in diabetic patients ${ }^{[56,57]}$. Liu et al also proposed that diabetes may increase $\beta$-amyloid in the cerebral cortices and hippocampi of rats and that this is a significant cause of memory impairment in diabetic animals ${ }^{[53]}$. Furthermore, alterations in P-GP expression have been shown to trigger the development of sugar cataracts, one of the many complications of diabetes ${ }^{[55]}$. All of these results indicate that alterations in P-GP expression and function are important to elucidate the mechanisms of the development of diabetic complications. However, the mechanisms and factors that result in tissue-specific alterations of P-GP need to be further investigated.

In summary, our present study demonstrates that alterations in the expression and function of $A b c b 1 / P-G P$ under diabetic conditions are tissue specific, $A b c b 1$ isoform specific and diabetic duration dependent. These results provide useful information for the elucidation of drug interactions and pharmacokinetic variability associated with diabetes mellitus.

\section{Acknowledgements}

The work was supported by the National Natural Science Foundation of China (№ 81072693 and 30672499) and the BASF Innovation Fund 2010.

\section{Author contributions}

Lu-lu ZHANG and Xiao-dong LIU designed the experiments and analyzed the data; Lu-lu ZHANG wrote the paper; Xiaodong LIU and Li LIU revised the paper; Lu-lu ZHANG, Liang LU, Shi JIN, Xin-yue JING, Dan YAO, Nan HU, and Ru DUAN performed the research; and Guang-ji WANG and Lin XIE contributed new analytic tools.

\section{References}

1 Bae SK, Yang SH, Lee SJ, Kwon JW, Kim WB, Lee DC, et al. Pharmacokinetic changes of DA-7867, a new oxazolidinone, after intravenous and oral administration to rats with short-term and long-term diabetes mellitus induced by streptozotocin. Eur J Pharm Sci 2005; 25: 337 45.

2 Kim YC, Oh EY, Kim SH, Lee MG. Pharmacokinetics and pharmacodynamics of intravenous torasemide in diabetic rats induced by alloxan or streptozotocin. Biopharm Drug Dispos 2005; 26: 371-8.

$3 \mathrm{Kim}$ YC, Oh EY, Kim SH, Lee MG. Pharmacokintics of diclofenac in rat model of diabetes mellitus induced by alloxan or steptozotocin. Biopharm Drug Dispos 2006; 27: 85-92.

4 Brady JM, Cherrington NJ, Hartley DP, Buist SC, Li N, Klaassen CD. Tissue distribution and chemical induction of multiple drug resistance genes in rats. Drug Metab Dispos 2002; 30: 838-44.

5 Marchetti S, Mazzanti R, Beijnen JH, Schellens JH. Concise review: clinical relevance of drug drug and herb drug interactions mediated by the ABC transporter ABCB1 (MDR1, P-glycoprotein). Oncologist 2007; 12: $927-41$.

6 Dey S, Patel J, Anand BS, Jain-Vakkalagadda B, Kaliki P, Pal D, et al. Molecular evidence and functional expression of P-glycoprotein (MDR1) in human and rabbit cornea and corneal epithelial cell lines. Invest Ophthalmol Vis Sci 2003; 44: 2909-18.

7 Fromm MF. Importance of P-glycoprotein at blood-tissue barriers. Trends Pharmacol Sci 2004; 25: 423-9.

8 Nishio N, Katsura T, Ashida K, Okuda M, Inui K. Modulation of P-glycoprotein expression in hyperthyroid rat tissues. Drug Metab Dispos 2005; 33: 1584-7.

9 Yu DK. The contribution of P-glycoprotein to pharmacokinetic drugdrug interactions. J Clin Pharmacol 1999; 39: 1203-11.

10 Liu XD, Pan GY, Xie L, Hou YY, Lan W, Su Q, et al. Cyclosporine A enhanced protection of nimodipine against brain damage induced by hypoxia-ischemia in mice and rats. Acta Pharmacol Sin 2002; 23: 
225-9.

11 Lickteig AJ, Fisher CD, Augustine LM, Aleksunes LM, Besselsen DG, Slitt AL, et al. Efflux transporter expression and acetaminophen metabolite excretion are altered in rodent models of nonalcoholic fatty liver disease. Drug Metab Dispos 2007; 35: 1970-8.

12 Naud J, Michaud J, Boisvert C, Desbiens K, Leblond FA, Mitchell A, et al. Down-regulation of intestinal drug transporters in chronic renal failure in rats. J Pharmacol Exp Ther 2007; 320: 978-85.

13 Tada Y, Wada M, Kuroiwa K, Kinugawa N, Harada T, Nagayama J, et al. MDR1 gene overexpression and altered degree of methylation at the promoter region in bladder cancer during chemotherapeutic treatment. Clin Cancer Res 2000; 6: 4618-27.

14 Yu S, Yu Y, Liu L, Wang X, Lu S, Liang Y, et al. Increased plasma exposures of five protoberberine alkaloids from Coptidis Rhizoma in streptozotocin-induced diabetic rats: is P-GP involved? Planta Med 2010; 76: 876-81.

15 Liu H, Zhang D, Xu X, Liu X, Wang G, Xie L, et al. Attenuated function and expression of P-glycoprotein at blood-brain barrier and increased brain distribution of phenobarbital in streptozotocin-induced diabetic mice. Eur J Pharmacol 2007; 561: 226-32.

16 Liu H, Xu X, Yang Z, Deng Y, Liu X, Xie L. Impaired function and expression of P-glycoprotein in blood-brain barrier of streptozotocininduced diabetic rats. Brain Res 2006; 1123: 245-52.

17 Nawa A, Fujita Hamabe W, Tokuyama S. Inducible nitric oxide synthase-mediated decrease of intestinal P-glycoprotein expression under streptozotocin-induced diabetic conditions. Life Sci 2010; 86: 402-9.

18 Tramonti G, Xie P, Wallner El, Danesh FR, Kanwar YS. Expression and functional characteristic of tubular transporters: P-glycoprotein, PEPT1, and PEPT2 in renal mass reduction and diabetes. Am J Physiol Renal Physiol 2006; 291: 972-80.

19 van Waarde WM, Verkade HJ, Wolters H, Havinga R, Baller J, Bloks $V$, et al. Differential effects of streptozotocin-induced diabetes on expression of hepatic ABC-transporters in rats. Gastroenterology 2002; 122: 1842-52.

20 Kamei J, Hirano S, Miyata S, Saitoh A, Onodera K. Effects of firstand second-generation histamine-H1-receptor antagonists on the pentobarbital-induced loss of the righting reflex in streptozotocininduced diabetic mice. J Pharmacol Sci 2005; 97: 266-72.

21 Ke LD, Chen Z, Yung WK. A reliability test of standard-based quantitative PCR: exogenous vs endogenous standards. Mol Cell Probes 2000; 14: 127-35.

22 Liu W, Saint DA. Validation of a quantitative method for real time PCR kinetics. Biochem Biophys Res Commun 2002; 294: 347-53.

23 Livak KJ, Schmittgen TD. Analysis of relative gene expression data using real-time quantitative PCR and the $2^{-\Delta \Delta c t}$ method. Methods 2001; 25: 402-8.

24 Applied-Biosystems. Relative quantitation of gene expression. User Bulletin \#2. ABI PRISM 7700 Sequence Detection System. 1997.

25 Jing X, Liu X, Wen T, Xie S, Yao D, Liu X, et al. Combined effects of epileptic seizure and phenobarbital induced overexpression of P-glycoprotein in brain of chemically kindled rats. $\mathrm{Br} J$ Pharmacol 2010; 159: 1511-22.

26 Schinkel AH, Smit JJ, van Tellingen O, Beijnen JH, Wagenaar E, van Deemter L, et al. Disruption of the mouse mdr1a P-glycoprotein gene leads to a deficiency in the blood-brain barrier and to increased sensitivity to drugs. Cell 1994; 77: 491-502.

27 Bond TD, Valverde MA, Higgins CF. Protein kinase C phosphorylation disengages human and mouse-1a P-glycoproteins from influencing the rate of activation of swelling-activated chloride currents. J Physiol 1998; 508: 333-40.
28 Lecureur V, Thottassery JV, Sun D, Schuetz EG, Lahti J, Zambetti GP, et al. Mdr1b facilitates p53-mediated cell death and p53 is required for Mdr1b upregulation in vivo. Oncogene 2001; 20: 303-13.

29 Zhou G, Kuo MT. Wild-type p53-mediated induction of rat mdr1b expression by the anticancer drug daunorubicin. J Biol Chem 1998; 273: 15387-94.

30 Ziemann C, Bürkle A, Kahl GF, Hirsch-Ernst KI. Reactive oxygen species participate in mdr1b mRNA and P-glycoprotein overexpression in primary rat hepatocyte cultures. Carcinogenesis 1999; 20: 40714.

31 Liu H, Liu X, Jia L, Liu Y, Yang H, Wang G, et al. Insulin therapy restores impaired function and expression of P-glycoprotein in bloodbrain barrier of experimental diabetes. Biochem Pharmacol 2008; 75: 1649-58.

32 Liu H, Yang H, Wang D, Liu Y, Liu X, Li Y, et al. Insulin regulates P-glycoprotein in rat brain microvessel endothelial cells via an insulin receptor-mediated PKC/NF-KB pathway but not a PI3K/Akt pathway. Eur J Pharmacol 2009; 602: 277-82.

33 Kameyama N, Arisawa S, Ueyama J, Kagota S, Shinozuka K, Hattori $A$, et al. Increase in P-glycoprotein accompanied by activation of protein kinase $\mathrm{C}$ alpha and NF-kappaB p65 in the livers of rats with streptozotocin-induced diabetes. Biochim Biophys Acta 2008; 1782: 355-60.

34 Barta CA, Sachs-Barrable K, Feng F, Wasan KM. Effects of monoglycerides on P-glycoprotein: modulation of the activity and expression in Caco-2 cell monolayers. Mol Pharm 2008; 5: 863-75.

35 Nishimura A, Honda N, Sugioka N, Takada K, Shibata N. Evaluation of carbamazepine pharmacokinetic profiles in mice with kainic acidinduced acute seizures. Biol Pharm Bull 2008; 31: 2302-8.

36 Pires MM, Emmert D, Hrycyna CA, Chmielewski J. Inhibition of P-glycoprotein-mediated paclitaxel resistance by reversibly linked quinine homodimers. Mol Pharmacol 2009; 75: 92-100.

37 Tanaka S, Masuda M, Nakajima K, Ido N, Ohtsuka T, Nishida M, et al. P-glycoprotein function in peripheral $T$ lymphocyte subsets of myasthenia gravis patients: clinical implications and influence of glucocorticoid administration. Int Immunopharmacol 2009; 9: 28490.

38 Tomita M, Kishimoto H, Takizawa Y, Hayashi M. Effects of intestinal ischemia/reperfusion on P-glycoprotein mediated biliary and renal excretion of rhodamine123 in rat. Drug Metab Pharmacokinet 2009; 24: 428-37.

39 Kato R, Moriguchi J, Irie T, Nakagawa M, Kusukawa Y, Matsumura H, et al. Effects of lipopolysaccharide on P-glycoprotein expression and activity in the liver and kidneys. Eur J Pharmacol 2010; 636: 155-8.

40 Cermanova J, Fuksa L, Brcakova E, Hroch M, Kucera O, Kolouchova G, et al. Up-regulation of renal Mdr1 and Mrp2 transporters during amiodarone pretreatment in rats. Pharmacol Res 2010; 61: 129-35.

41 Borbás T, Benko B, Dalmadi B, Szabó I, Tihanyi K. Insulin in flavincontaining monooxygenase regulation. Flavin-containing monooxygenase and cytochrome P450 activities in experimental diabetes. Eur J Pharm Sci 2006; 28: 51-8.

42 Huber JD, VanGilder RL, Houser KA. Streptozotocin-induced diabetes progressively increases blood-brain barrier permeability in specific brain regions in rats. Am J Physiol Heart Circ Physiol 2006; 291 : 2660-8.

43 Hawkins BT, Davis TP. The blood-brain barrier/neurovascular unit in health and disease. Pharmacol Rev 2005; 57: 173-85.

44 Hawkins BT, Ocheltree SM, Norwood KM, Egleton RD. Decreased blood-brain barrier permeability to fluorescein in streptozotocintreated rats. Neurosci Lett 2007; 411: 1-5.

45 Goralski KB, Hartmann G, Piquette-Miller M, Renton KW. Down- 
regulation of mdr1a expression in the brain and liver during CNS inflammation alters the in vivo disposition of digoxin. Br J Pharmacol 2003; 139: 35-48.

46 Kathryn T. Dyslipidaemia, inflammation and endothelial dysfunction in diabetes mellitus. Int Congr Ser 2004; 1262: 511-4.

47 Tambur AR, Markham PN, Gebel HM. IL-4 Inhibits P-Glycoprotein in normal and malignant NK cells. Hum Immunol 1998; 59: 483-7.

48 Liu YC, Liu HY, Yang HW, Wen T, Shang Y, Liu XD, et al. Impaired expression and function of breast cancer resistance protein (Bcrp) in brain cortex of streptozocin-induced diabetic rats. Biochem Pharmacol 2007; 74: 1766-72.

49 Zhao YL, Du J, Kanazawa H, Sugawara A, Takagi K, Kitaichi K, et al. Effect of endotoxin on doxorubicin transport across blood-brain barrier and P-glycoprotein function in mice. Eur J Pharmacol 2002; 445: 115-23.

50 Heemskerk S, van Koppen A, van den Broek L, Poelen GJ, Wouterse AC, Dijkman HB, et al. Nitric oxide differentially regulates renal ATPbinding cassette transporters during endotoxemia. Pflugers Arch 2007; 454: 321-34.

51 Anger GJ, Magomedova L, Piquette-Miller M. Impact of acute streptozotocin-induced diabetes on $A B C$ transporter expression in rats. Chem Biodivers 2009; 6: 1943-59.
52 Reichel V, Burghard S, John I, Huber O. P-glycoprotein and breast cancer resistance protein expression and function at the bloodbrain barrier and blood-cerebrospinal fluid barrier (choroid plexus) in streptozotocin-induced diabetes in rats. Brain Res 2011; 1370: 238-45.

53 Liu Y, Liu H, Yang J, Liu X, Lu S, Wen T, et al. Increased amyloid betapeptide (1-40) level in brain of streptozotocin-induced diabetic rats. Neuroscience 2008; 153: 796-802.

54 Ueda K, Okamura N, Hirai M, Tanigawara Y, Saeki T, Kioka N, et al. Human P-glycoprotein transports cortisol, aldosterone, and dexamethasone, but not progesterone. J Biol Chem 1992; 267: 2424852.

55 Miyazawa T, Kubo E, Takamura Y, Akagi Y. Up-regulation of P-glycoprotein expression by osmotic stress in rat sugar cataract. Exp Eye Res 2007; 84: 246-53.

56 Anderson RJ, Freedland KE, Clouse RE, Lustman PJ. The prevalence of comorbid depression in adults with diabetes: a meta-analysis. Diabetes Care 2001; 24: 1069-78.

57 Goodyer IM, Herbert J, Tamplin A, Altham PM. First-episode major depression in adolescents. Affective, cognitive and endocrine characteristics of risk status and predictors of onset. Br J Psychiatry 2000; 176: 142-9. 